LA.7602-MS

Informal Report

UC-4

Issued: February 1979

\title{
Stability of the Lanthanide Hydrides
}

Dean H.W. Carstens
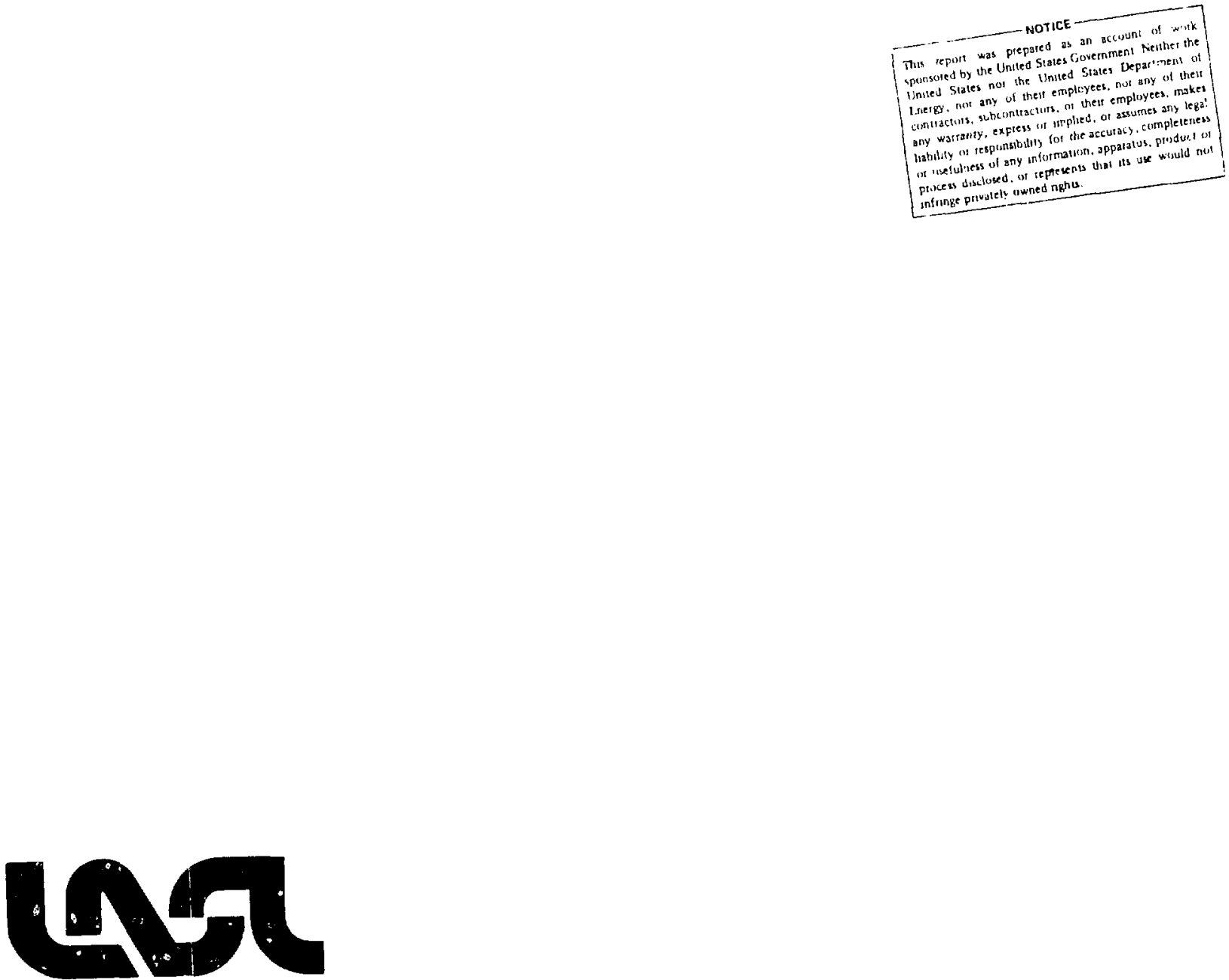


\title{
STABILITY OF THE LANTHANIDE HYDRIDES
}

\author{
by
}

\author{
Dean H. W. Carstens
}

\begin{abstract}
A review of the unclassified literature is presented that tabulates the reported equilibrium pressure data of the lanthanide diprotides and dideuterides in the form $\log P($ torr $)=\mathbf{A} / \mathbf{T}+\mathbf{B}$. Values of the thermodynamic properties are tabuiated and the trend in those data is explained by several semiempirical formulas. The isotope shifts are calculated by two independent means. For any lanthanide metal, the heat of formation of the dihydride is about $1.5 \mathrm{kcal} /$ mole more negative than the dideuteride, which, in turn, is about $0.5 \mathrm{kcal} / \mathrm{mole}$ more negative than the ditritide. These values agree well with the experimental values.
\end{abstract}

\section{INTRODUCTION}

The hydrides of the lanthanide metals are among the most stable, and because of this stability they have potential applications in energy-related fields. It is time to look at the thermodynamic properties of the lanthanide dihydrides. Although a!l the lanthanide hydrides except $\mathrm{EuH}_{2}$ react further to form trihydrides, they will not be discussed here.

Experimental data for the lanthanide diprotides, dideuterides, and in one case ditritide, are listed and discussed, relying heavily on previous reviews $\mathrm{s}^{1-4}$ and a computer search of the unclassified literature to April 19"\% 8 . Several theoretical and semiempirical approaches are used to rationalize the observed trends in the thermodynamic properties and to predict the isotope shifts.

The electronic structures of $\mathrm{EuH}_{2}$ and $\mathrm{YbH}_{2}$ are significantly different from the others because of their half-filled $\left(\mathrm{EuH}_{2}\right)$ or filled $\left(\mathrm{YbH}_{2}\right)$ f-orbitals. This should lead to increased stability and, perhaps becruse of increased experimental difficultias, their thermodynamic properties have not been reported. Data on the radioactive promethium have not been measured, but the remaining lanthanides are covered thoroughly in the literature. Data on scandium and yttrium are included here for comparison.

Reliable studies of the hydrides first appeared in the mid 1950s. Before that time, the pure metals were unavailable; therefore, all previous work is suspect. In the late 1950 s and early 1960 s, considerable work was done with the diprotides and dideuterides, previously reviewed by Mueller et al.,' Bos and Gayer, ${ }^{2}$ and Beavis. ${ }^{3}$ Unfortunately, the important work of Jones et al. ${ }^{.8}$ was overlooked.

\section{SUMMARY OF THE DATA}

The temperature variation of the equilibrium pressure of hydrogen over a lanthanide dihydride can be represented by the relationship

$\log P($ torr $)=A / T+B$, 
where $A$ and $B$ are constants and $T$ is the absoluie temperature. From the values of the two constants, estimates of the thermodynamic properties can be calculated from three relationships.

$\Delta \mathrm{H}^{\circ}=2.303 \mathrm{RA}$,

$\Delta \mathrm{S}^{\circ}=\mathrm{R} \ln 760-2.303 \mathrm{RB}$,

and

$\Delta F^{\circ}=\Delta H^{\circ}-\mathrm{T}^{\mathrm{T}} \Delta \mathrm{S}^{\circ}$,

where $\Delta \mathrm{H}^{\circ}, \Delta \mathrm{S}^{\circ}$, and $\Delta \mathrm{F}^{\circ}$ are the standard enthalpy, entropy, and free energy of formation and $\mathrm{R}$ is the gas constant. These equations hold only for ideal, stoichiometric hydrides, which the lanthanide hydrides only approximate.

Table I summarizes the reported experimental data $[A$ and $B$ in $E(j . ~(1)]$ for the lanthanide hydrides and deutericies and the values of the thermodynamic functions calculated from these constants. The experimental statistical error on $A$ and $B$ reported by most authors is not listed in this table. Several effects, such as impure samples, lack of equilibrium, systematic errors in temperature and pressure measurements, and isotopic impurities, can lead to errors in measurements. I believe that the roported statistical errors, generally 0.1 to $1 \%$, are toc optimistic and do not reflect reliably the data's accuracy. The data obtained for a given hydride by different authors usually fall outside the published errors.

Jones $^{\circ}$ used a mass-spectrometric comparison technioue tc look at the differences between the equilibrium pressures of $\mathrm{ErD}_{2}$ and $\operatorname{ErT}_{2}$. He found the ratio of the dideuteride pressure to the ditritide to be 0.91 , continuing the stability trends seen in Table I.

Comparing the data in Table I, the work described in Refs. 7 and 5 appears more reliable. Korst and Warf ${ }^{7}$ studied lanthanum, cerium, praseodymium, and neodymium, and Jones et al. ${ }^{\mathbf{5}}$ looked at yttrium, praseodymium, and the later elements terbium, dysprosium, holmium, erbium, thulium, and lutetium. In the following discussion, I give more consideration to the clata of these authors because (1) thei: data appear more accurate when the whole data set is considered; (2) their values for praseodymium are in good agreement; and (3) relative data for a series of elements done by a group of authors should be more reliable because the same techniques are used.

The various thermodynamic values calculated from the pressure data listed in Table $I$ are plotted in Fig. 1 for the diprotides and in Fig. 2 for the dideuterides, where the two preferred sets of data are indicated with solid circles. The lines are drawn more to connect thair points rather than to indicate the correct trend. However, a general trend seems evident. There is a gradual increase in all values as the atomic weight increases with a definite drop at lutetium and probable drop at gadolinium. This trend is discussed in the next section.

\section{IiI. RELATIVE STABILITIES}

No comprehensive theory of metal hydride stability has been proposed, primarily because of the wide variations in characteristics. A theoretical treatment of the lanthanide hydrides is particularly difficult because they are neither ionic nor covalent, but belong to the group of metallic hydrides. Nevertheless, several empirical and semiempirical treatments have been advanced and in this section they are applied to the set of dista presented in the preceding section.

Mulford ${ }^{\theta}$ was the first to at lempt to rationalize the variations in $\Delta \mathrm{H}$. He obtained approximately linear relationship by plotting, the product of the molar volume of the hydride and its heat of formation against atomic number. Unfortunately, most of his reported data were estimated by all undisclosed thermodynamic method and it is difficult to judge the data's accuracy. He did predict that the stabilities should increase monotonically down the series, maximizing at erbium which is almost correct. Similarly, Magee ${ }^{\theta}$ plotted the free energy versus the room-temperature latiice parameter of the dihydrides, again obtaining an approximately linear plot. Scandium hydride did not fit the empirical curve, although yttrium did. Figure 3 shows a similar plot using the preferred set of data developed in the previous section. Note that except for lutetium, terbium, gadolinium (and scandium, which is well off the curve), a fairly regular trend maximizing at holmium and dysprosium is seen.

Magee $^{9}$ also proposed plctting the free energy versus the ratio of metal-to-metal distance in the 
TABLE I

\section{EXPERIMENTAL THERMODYNAMIC PROPERTIES OF THE LANTHANIDE HYDRIDES AND DEUTERIDES

\author{
$\log _{10} P($ torr $)=A / T+B$
}

\begin{tabular}{|c|c|c|c|c|c|c|c|c|c|c|c|c|}
\hline \multirow{2}{*}{$\begin{array}{l}\text { Atomic } \\
\text { Number }\end{array}$} & \multirow[b]{2}{*}{ Element } & \multirow[b]{2}{*}{ Ref. } & \multicolumn{5}{|c|}{ Hydride } & \multicolumn{5}{|c|}{ Deuteride } \\
\hline & & & $-\mathbf{A}$ & $\mathrm{B}$ & $-\Delta \mathbf{H}^{\circ}$ & $-\Delta S^{\circ}$ & $-\Delta \mathbf{F}^{\circ}$ & $-\mathbf{A}$ & $\mathbf{B}$ & $-\Delta \mathbf{H}^{\circ}$ & $-\Delta \mathrm{s}^{\circ}$ & $-\Delta F^{\circ}$ \\
\hline 21 & $\mathrm{Sc}$ & $\begin{array}{r}4 \\
13 \\
3\end{array}$ & $\begin{array}{r}9050 \\
10490\end{array}$ & $\begin{array}{r}9.17 \\
10.48\end{array}$ & $\begin{array}{l}41.4 \\
48.0 \\
47.8\end{array}$ & $\begin{array}{l}28.8 \\
34.8 \\
34.9\end{array}$ & $\begin{array}{l}33.6 \\
38.5 \\
38.3\end{array}$ & & & & & \\
\hline .39 & $Y$ & $\begin{array}{r}14 \\
15 \\
5\end{array}$ & $\begin{array}{r}11870 \\
9710\end{array}$ & $\begin{array}{r}10.52 \\
8.80\end{array}$ & $\begin{array}{l}54.3 \\
44.4\end{array}$ & $\begin{array}{l}35.0 \\
27.1\end{array}$ & $\begin{array}{l}44.8 \\
37.0\end{array}$ & 11300 & 10.15 & 51.7 & 33.8 & 42.6 \\
\hline 57 & $\mathrm{La}$ & $\begin{array}{r}16 \\
7 \\
3\end{array}$ & $\begin{array}{l}10860 \\
10850\end{array}$ & $\begin{array}{l}10.76 \\
10.64\end{array}$ & $\begin{array}{l}49.7 \\
49.7 \\
49.6\end{array}$ & $\begin{array}{l}36.1 \\
35.5 \\
35.6\end{array}$ & $\begin{array}{l}39.9 \\
40.0 \\
39.9\end{array}$ & 10170 & 10.11 & $\begin{array}{l}46.5 \\
46.6\end{array}$ & $\begin{array}{l}33.1 \\
33.5\end{array}$ & $\begin{array}{l}37.5 \\
37.5\end{array}$ \\
\hline 58 & $\mathrm{Ce}$ & $\begin{array}{r}16 \\
7 \\
17\end{array}$ & $\begin{array}{r}7420 \\
10760 \\
12000\end{array}$ & $\begin{array}{r}7.71 \\
10.63 \\
11.90\end{array}$ & $\begin{array}{l}33.9 \\
49.2 \\
54.9\end{array}$ & $\begin{array}{l}22.1 \\
35.5 \\
41.3\end{array}$ & $\begin{array}{l}27.9 \\
39.6 \\
43.6\end{array}$ & 10120 & 10.21 & 46.3 & 33.5 & 37.2 \\
\hline 59 & $\operatorname{Pr}$ & $\begin{array}{r}16 \\
7 \\
5\end{array}$ & $\begin{array}{l}10+50 \\
10870 \\
10940\end{array}$ & $\begin{array}{l}10.23 \\
10.53 \\
10.56\end{array}$ & $\begin{array}{l}47.8 \\
49.7 \\
50.1\end{array}$ & $\begin{array}{l}333.6 \\
35.0 \\
35.1\end{array}$ & $\begin{array}{l}38.6 \\
40.2 \\
40.5\end{array}$ & 10490 & $\mathrm{i} 0.25$ & 48.0 & 33.7 & .28 .8 \\
\hline 60 & Nd & $\begin{array}{r}16 \\
7\end{array}$ & $\begin{array}{r}9800 \\
11030\end{array}$ & $\begin{array}{r}9.37 \\
10.48\end{array}$ & $\begin{array}{l}44.8 \\
50.5\end{array}$ & $\begin{array}{l}29.7 \\
34.8\end{array}$ & $\begin{array}{l}36.7 \\
41.0\end{array}$ & & & & & \\
\hline 61 & $\mathrm{Pm}$ & & & & & & & & & & & \\
\hline 62 & $\mathrm{Sm}$ & 8 & 11700 & 11.4 & 53.5 & 39.0 & 42.9 & & & & & \\
\hline 6.3 & Eu & & & & & & & & & & & \\
\hline 64 & $\mathrm{Gd}$ & 18 & 10250 & 9.72 & 46.9 & 31.3 & 38.4 & & & & & \\
\hline 65 & $\mathrm{~Tb}$ & 5 & 11320 & 20.38 & 51.8 & 343 & 42.4 & 10840 & 10.24 & 49.6 & 33.7 & 40.4 \\
\hline 66 & Пу & 5 & 12120 & 11.16 & 55.5 & 37.9 & 45.1 & 11410 & 10.54 & 52.2 & 35.1 & 42.6 \\
\hline 67 & Ho & $\begin{array}{r}5 \\
19\end{array}$ & $\begin{array}{l}12120 \\
11520\end{array}$ & $\begin{array}{l}11.10 \\
10.66\end{array}$ & $\begin{array}{l}55.5 \\
52.7\end{array}$ & $\begin{array}{l}37.6 \\
35.6\end{array}$ & $\begin{array}{l}45.2 \\
43.0\end{array}$ & $\begin{array}{l}11630 \\
11420\end{array}$ & $\begin{array}{l}10.93 \\
10.70\end{array}$ & $\begin{array}{l}53.2 \\
52.3\end{array}$ & $\begin{array}{l}36.8 \\
35.8\end{array}$ & $\begin{array}{l}43.2 \\
42.5\end{array}$ \\
\hline 68 & Er & $\begin{array}{r}20 \\
8 \\
5\end{array}$ & $\begin{array}{l}11900 \\
12070\end{array}$ & $\begin{array}{l}11.0 \\
11.16\end{array}$ & $\begin{array}{l}52.6 \\
54.5 \\
55.2\end{array}$ & $\begin{array}{l}35.2 \\
37.2 \\
37.9\end{array}$ & $\begin{array}{l}43.0 \\
44.3 \\
44.9\end{array}$ & 11430 & 10.62 & $\begin{array}{l}52.9 \\
52.3\end{array}$ & $\begin{array}{l}35.8 \\
35.4\end{array}$ & $\begin{array}{l}43.1 \\
42.6\end{array}$ \\
\hline 69 & $\operatorname{Tm}$ & 5 & 11750 & 10.82 & 53.8 & 36.3 & 43.8 & 11260 & 10.80 & 51.5 & 36.2 & 41.6 \\
\hline 70 & $\mathrm{Yb}$ & & & & & & & & & & & \\
\hline 71 & $\mathrm{Lu}$ & 5 & 10730 & 10.20 & 49.1 & 33.5 & 40.0 & 10340 & 9.78 & 47.3 & 31.6 & 38.7 \\
\hline
\end{tabular}




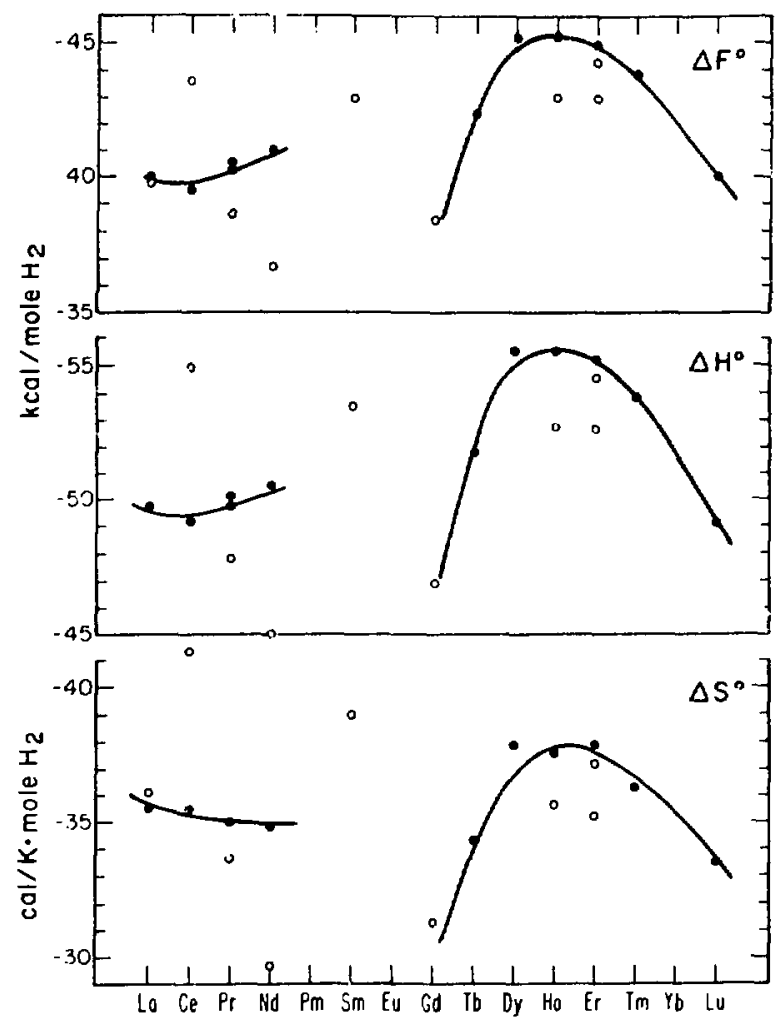

Fig. 1.

Experimental values of $\Delta F^{\circ}, \Delta H^{\circ}$, and $\Delta S^{\circ}$ for the formation of lanthanide diprotides.

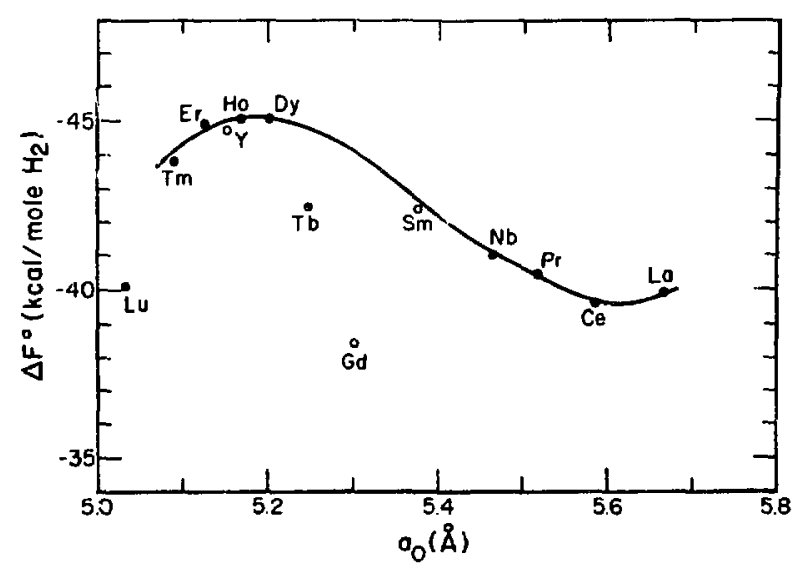

Fig. 3.

Variation of $\Delta F^{\circ}$ versus the lattice parameter for the lanthanide diprotides.
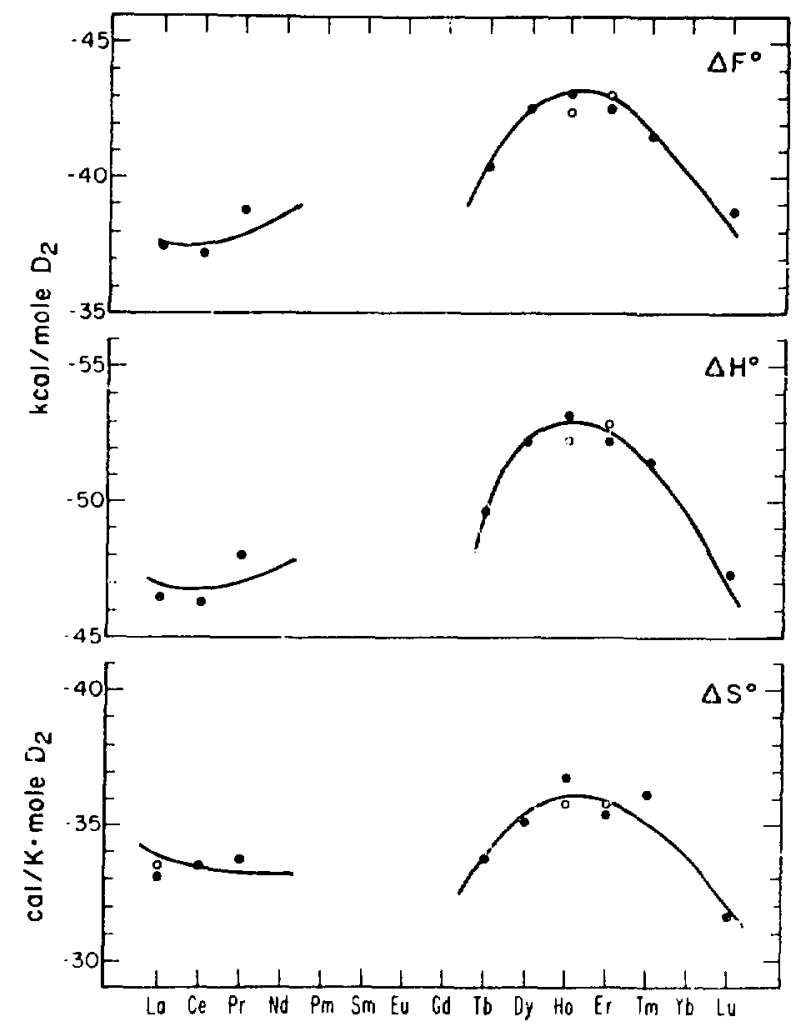

Fig. 2.

Experimental values of $\Delta F^{\circ}, \Delta H^{\circ}$, and $\Delta S^{\circ}$ for the formation of lanthanide dideuterides.

pure metal to that in the hydride. He thought that as the metal-to-metal distance increased on hydriding, the metallic covalent cohesive bonding should decrease, thereby leading to decreased hydride stability. He again found that scandium did not fit the trends and suggested that perhaps there was a ratio giving maximum stability. Figure 4 shows such a plot for our set of data. Note that although there is a general increase in stability as the ratio approaches unity, gadolinium, scundium, lutetium, and yttriums again do not fit. None of these approaches suggests reasons for these variations. Also, because dideuterides have similar interatomic distances to the dihydrides, these methods do not explain the differences in the isotope stabilities.

A less empirical approach is through the use of the Boin-Haber cycle and a calsulated lattice energy. 


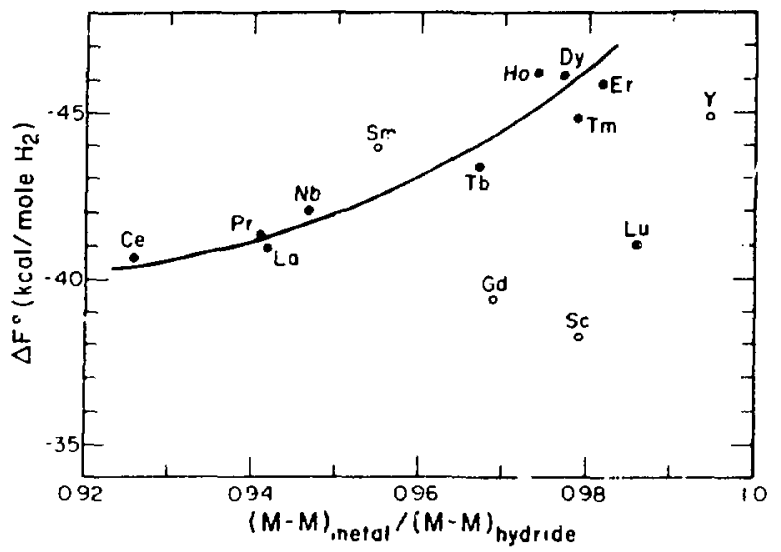

Fig. 4.

Variation of $د F^{\circ}$ versus the ratio of the metalto-metal distance in the pure lanthanide to that in the diprotide.

With this cycle, Gibb ${ }^{10}$ showed that the heat of formation of the dihydride is given by

$\left.د H=I^{\prime}+S+I\right)+1+2 H$.

where $S$ is the sublimation energy of the metal lanthanide, $I$ is the sum of its first and second jonjzation potentials, $D$ is the dissociation energy of the hydrogen inolecule, and $\mathrm{E}$ is the electron affinity of the neutral $h y d$ drogen atom. $U$ is the lattice energy, defined as the heat of the reaction

$\mathrm{M}^{+}(\mathrm{g})+2 \mathrm{H}^{-}(\mathrm{g})=\mathrm{MH}_{2}(\mathrm{~s})$.

Gibb suggested using the Born-Larde equation

$U=-3.30 A(1-1 / n) / d_{111}$.

where $A$ is the Madelung constant, $\mathrm{d}_{\mathrm{MH}}$ is the metalto-hydrogen distance, and $\mathrm{n}$ is an empirical constant, to calculate U. With this method, he estimated fairly reasonable values of $U$ for ionic hydrides, although it failed with covalent hydrides, as expected.

Polyachenok and Novikov" followed this approach in studying the stabilities of the lanthanide dichlorides. They predicted and observed a trend analogous to that seen above for the hydrides with sharp drops in the stability curves at gadolinium and lutetium. The results of these calculations for the lanthanide dihydrides are presented in Table II, using the ionization potentials suggested by Polyachenok and Novikov. Although the results compare poorly with the experimental values, similar trends are seen in the calculated $\mathrm{SH}^{\circ}$. As seen in Table II, the drops in the middle and end of the series can be attributed directly to the change: in $s$, the heat of sublimation. Thus it seems probable that the discontinuities in the measured $\Delta H^{\circ}$ values can be traced to the variations in $S$.

\section{ISOTOPIC SHIFTS}

Aithough the lattice energy approach failed to predict quantitatively the differences seen across the lanthanide series, the method should be more successful in predicting the smaller isotope shift. As indicated by Eq. (5), because $S$ and I are characteristic of the metal only, they would not change if the hydrogen isotope were changed. Also, the electron affinity should be the same for the three hydrogen isotopes because it is a property of the electronic orbitals only. Therefore, only the lattice energy $U$ and the dissociation nergy $D$ should be effective in

TABLE II

\section{BORN-HABER CALCULATIONS OF} THE LANTHANIDE DIHYDH:STS

\begin{tabular}{|c|c|c|c|c|c|c|c|}
\hline \multirow[b]{2}{*}{ M } & \multirow[b]{2}{*}{$\underline{\mathbf{d}_{M M}}$} & \multirow[b]{2}{*}{$-\mathbf{U}^{\mathbf{n}}$} & \multirow[b]{2}{*}{$2 \mathbf{E}+\mathbf{D}$} & \multirow[b]{2}{*}{$\underline{\mathbf{s}}$} & \multicolumn{2}{|c|}{1} & \multirow[b]{2}{*}{$\Delta \mathbf{H}^{\circ}$} \\
\hline & & & & & Exp & Est & \\
\hline $\mathrm{La}$ & 2.83 & 525 & +73 & 97 & 391 & 390 & +35 \\
\hline $\mathrm{Ce}$ & 2.79 & 533 & +73 & 96 & & 390 & +26 \\
\hline $\mathrm{Pr}$ & 2.76 & 539 & +73 & 78 & 382 & 390 & +2.3 \\
\hline $\mathrm{Nd}$ & 2.73 & 544 & +73 & 76 & 386 & 390 & -5 \\
\hline $\mathrm{Pm}$ & 2.71 & 548 & +73 & 62 & & 390 & -24 \\
\hline $\mathrm{Sm}$ & 2.69 & 553 & +73 & 50 & 391 & 390 & -40 \\
\hline $\mathbf{E u}$ & 2.67 & 557 & +73 & 42 & 389 & 390 & -52 \\
\hline Gd & 2.65 & 560 & +73 & 84 & & 420 & 32 \\
\hline $\mathrm{Tb}$ & 2.62 & 567 & +73 & 87 & & 420 & 29 \\
\hline Dy & 2.60 & 572 & +73 & 62 & & 420 & -1 \\
\hline Ho & 2.58 & 577 & +73 & 70 & & 420 & +2 \\
\hline $\mathrm{Er}$ & 2.56 & 581 & +73 & 66 & & 420 & -6 \\
\hline $\mathrm{Tm}$ & 2.55 & 583 & +73 & 58 & & 420 & -16 \\
\hline$Y b$ & 2.53 & 588 & +73 & 40 & 423 & 420 & -39 \\
\hline Lu & 2.52 & 590 & +73 & 95 & & 420 & 14 \\
\hline
\end{tabular}

${ }^{\mathrm{U}} \mathrm{U}=-3.30(5.04) / \mathrm{d}_{\mathrm{MM}}[1-1 / 9.5]$. 
calculating the isotope shift. Generaliv, the lattice parameter of the protides is about $0.2 \%$ greater than that of the deuterides. From this difference, Eq. (7) indicates that $U$ should be abcut $0.5 \mathrm{kcal} / \mathrm{mole}$ more negative for $\mathrm{LnD}_{2}$ than for $\mathrm{LnH}_{2}$. But the dissociation energy of $D_{2}$ is $2 \mathrm{kcal} / \mathrm{mole}$ greater (more positive; than for $H_{2}$. The result is that $\Delta \mathrm{H}^{\circ}$ for $\mathrm{LnD}_{2}$ should be about $1.5 \mathrm{kcal} / \mathrm{mole}$ less negative than $\mathrm{AH}^{\circ}$ for $\mathrm{I}_{1} \mathrm{H}_{2}$ for all the lanthanide metals. Table I shows that the dideuteride $\mathrm{i}$, always less stable than the diprotide by 1 to:3 kcal $/ \mathrm{mole}$, which agrees with the theory.

For the tritide-to-deuteride comparison, the lattice parameter should change even less, and the dissociation energy of tritium is about $0.8 \mathrm{kcal} / \mathrm{mole}$ more positive than for deuterium. Therefore, the tritide should be slightly less stable than the deuteride, but the differences will be smaller than for the deuteride and protide. These calculations neglect the zero-point energy, which is discussed below.

Another approach to calculating the isotope shift is through statistical mechanics. In his approach to palladium hydride, Lacher ${ }^{12}$ showed that for exothermic absorbers in which $\mathbf{M}_{\mathrm{a}}$ hydrogen atoms are arranged in $N_{B}$ available sites, the energy of a given hydrogen atom is given by

$E=-M_{H} W_{H}-1 / 2 M_{B}^{2} \mathcal{W}_{H H} / N_{\mathrm{B}}$,

where $W_{H}$ is the ear rgy of the atom in its site and $W_{11}$ is the interaction energy between different hydrogen atoms. From this assumption Lacher was able to show that the pressure within the plateau region could be expressed by

$$
\begin{aligned}
& \ln \mathrm{P}^{1 / 2}=-\left(1 / 2 \mathrm{~W}_{\mathrm{HH}}+\mathrm{W}_{\mathrm{H}}-1 / 2 \mathrm{D}\right) / \mathrm{kT} \\
& +\ln \left|\left(\mathrm{KTF}_{2}^{\prime}\right)^{1 / 2} / \mathrm{v}(\mathrm{T})\right|
\end{aligned}
$$

where $D$ is again the dissociation energy of the hydrogen molecule, $F_{2}$ is related to the partition function of the gaseous hydrogen molecule, and $v(T)$ is the partition function of the hydrogen atom in its site. If we now assume that the last logarithmic function is independent of temperature (which it is only approximately), then the heat of formation can be associated with the first term on the right-hand side of $\mathrm{F}_{\mathrm{z}}$. (9). Then by comparison with Eqs. (1) and (2),

$\Delta H^{\circ}=-W_{H H}-2 W_{H}+D$.

$W_{H}$ is the zero point energy and, if we assume the hydrogen atom behaves as an isjotropir ascillator, this is given by $W_{H}=-3 / 2 h \nu$, wh vibrational frequency. Further, because $\nu_{D}=$ $\nu_{H}\left(m_{H} / m_{D}\right)^{1 / 2}$, we can calculate this difference if we know one of the frequencies. As an estimute, we take $\nu_{H}=10^{18} \mathrm{~s}^{-1}$, which leads to $W_{H}-W_{D}=-400 \mathrm{kcal} /-$ mole and $W_{r}-W_{D}=-200 \mathrm{keal} / \mathrm{mole}$.

Lacher showed that $W_{H H}=4 k T_{C}$ where $T_{C}$ is the critical temperature of the hydride; that is, the temperature above which the two-phase system becomes one. This has not been measured for the lanthanides, therefore we must assume they are the same for all three isotopes. From these assumptions and Eq. (10) we can then calculate that $\Delta \mathrm{H}_{\mathrm{H}}^{\circ}-\Delta \mathrm{H}_{\mathrm{D}}^{\circ}$ $=-12 \mathrm{kcal} / \mathrm{mole}$ and $\Delta \mathrm{H}^{\circ}-\Delta \mathrm{H}_{\mathrm{j}}^{\circ}=-0.4 \mathrm{kcal} / \mathrm{mole}$ for ali the lanthanides, which agrees with the last calculations.

\section{REFERENCES}

1. W. M. Mueller, J. P. Blackledge, and G. C. Libowitz, Metal Hydrides (Academic Press, New York, 1968).

2. W. G. Bos and K. H. Gayer, "The Rare Earth Hydrides," J. Nucl. Mater. 18, 1-30 (1966).

3. L. C. Beavis, "Characteristics of Some Binary Transition Metal Hydriaes," J. Less-Common Met. 19, 315-328 (1J69).

4. R. L. Beck, "Research and Development of Metal Hydrides. Summary Report, October 1958 to September 1960," Denver Research Institute report: DRI-LAR-10 (1960).

5. F. M. S. Jones, J. Southali, and K. Goodhead, "Thermal Stability of Metal Hydrides. Part 1. Rare Earth and Yttrium Hydrides and Deuterides," Atomic Weapons Research Establishment report AWRE-0-22/64 (1964). 
6. P. M. S. Jones, "Thermal Stability of Metal Hydrides, Deuterides, and Tritides," Nature 223, 829-830 (1969).

7. W. L. Korst and J. C. Warf, "Rare EarthHydrogen Systems. I. Structural and Thermodynamic Properties," Inorg. Chem. 5, 17191726 (1966).

8. R. N. R. Mulford, "A Review of the Rare-Earth Hydrides," USAEC report AECU-3813 (1959).

9. R. L. Beck, "Investigation of Hydriding Characteristics of Intermetallic Compounds. Summary Report, 1 October 1960 to 31 October 1961," Denver Research Institute report DRILAR-55 (1961).

10. T. R. P. Gibb, elr., "Primary Solid Hydrides," Prog. Inorg. Chem. 3, 315-509 (1962).

11. O. G. Polyachenok and G. I. Novikov, "Stability of Chlorides of Low-Valent Rare-Earth Elen. ents, "Zh. Ncorg. Khim. (English Translation) 8, 816-820 (1963).

12. J. R. Lacher, "A Theoretical formula for the solubility of Hydrogen in Palladium," Proc. R. Soc. London A161, 525-545 (1937).

13. M. L. Lieberman and P. G. Wahlbeck, "Thermodynamics of the Scandium-Hydrogen System," J. Phys. Chem. 69, 3514-3519 (1465).
14. L. N. Yannopoulos, R. K. Edwards, and P. G. Wahlbeck, "Thermodynamics of the YttriumHydrogen System," J. Phys. Chem 69, 2510-2515 (1965).

15. C. E. Lundin and J. P. Blackledge, "PressureTemperature-Composition Relationship of the Yttrium-Hydrogen System," J. Electrochem. Soc. 109, 838-842 (1962).

16. R. N. R. Mulford and C. E. Holley, Jr., "Pressure-Temperature-Co!nposition Studies of Some Rare Earth/Hydrogen Systems," J. Phys. Chein. 59, 1222-1226 (1955).

17. R. Streck and K. Dialer, "Phase Behøvior and State of Order of Cerium Hydride," $\%$. Anorg. A!lg. Chem. 306, 141 (1960).

18. G. E. Sturdy and R. N. R. Mulford, "The Gadolinium-Hydrogen System," J. A:n. Chem. Soc. 78, 1083-1087 (1956).

19. F. C. Perkins and C. E. Lundin, "The HolsniumHydrogen System," J. Electrochem. Soc. 115, 2.1-24 (1968).

20. R. W. Sullivan and C. E. Lundin, "Irivestigation of Hydriding Characteristics of Intermetallic Compounds," Denver Research Institute report DRI-2379 (1967). 